\title{
Predation Risk Influences the Diving Behavior of a Marine Mesopredator
}

\author{
Meagan M. Dunphy-Daly ${ }^{1,2}$, Michael R. Heithaus ${ }^{*}, 1$, Aaron J. Wirsing ${ }^{1,3}$, Jerome S.F. Mardon ${ }^{4}$ and \\ Derek A. Burkholder ${ }^{1}$
}

\author{
${ }^{I}$ Department of Biological Sciences, Florida International University, 3000 NE 151 St, North Miami, FL, 33181, USA \\ ${ }^{2}$ Nicholas School of the Environment and Earth Sciences, Duke University, 135 Duke Marine Lab Road, Beaufort, NC, \\ 28516, USA \\ ${ }^{3}$ School of Forest Resources, University of Washington, Box 352100, Seattle, WA 98195, USA \\ ${ }^{4}$ Behavioural Ecology Research Group, CEFE CNRS Montpellier, 1919 Route de Mende, 34293 Montpellier Cedex 5, \\ France
}

\begin{abstract}
Exploring factors that influence diving behavior is critical to understanding energy budgets, habitat use, and exploitation rates of prey. Optimal diving behavior studies have focused primarily on trade-offs between oxygen recovery at the surface and energy intake at depth. General predictions from these models are often supported by empirical data, but a mismatch exists between theory and data that has led to increasingly complex models. Despite the importance of nonconsumptive predator effects in terrestrial and marine communities, the possibility that predation risk induces changes in diving behavior has only recently been recognized. We tested whether pied cormorants (Phalacrocorax varius) modify their diving behavior in response to spatio-temporal variation in tiger shark (Galeocerdo cuvier) abundance in the relatively pristine seagrass ecosystem of Shark Bay, Australia. As theory predicted, cormorants reduced the duration of the most dangerous component of the dive cycle by reducing the proportion of time spent at the surface as predation risk increased, but only in the most dangerous habitat. Contrary to model predictions, cormorants accomplished this reduction by increasing dive durations while maintaining similar post-dive surface intervals (leading to lower diving rates). By implication, foraging cormorants may be working harder during high-risk periods and in high-risk habitats to minimize their exposure to predators at the surface. Our finding that cormorants modify their diving behavior in response to spatial and temporal variation in predation risk suggests that the effects of predators on diving species may be greater, and manifest through more pathways, than is currently appreciated. Future studies of diving species, including those considered "top predators," must explicitly consider the potential importance of predation risk. Furthermore, diving behavior as an index of patch quality should be used cautiously when divers are threatened by predators, which is often the case.
\end{abstract}

Keywords: Diving behavior, predation risk, non-consumptive predator effects, ecology of fear, trade-offs.

\section{INTRODUCTION}

Air-breathing aquatic foragers (e.g., marine mammals, diving birds, aquatic reptiles) often are upper trophic level predators or the largest herbivores in marine communities and, as such, may play important structuring roles (Thayer $e t$ al. 1984, Preen 1995, Aragones \& Marsh 2000, Moran \& Bjorndal 2007). Therefore, identifying the factors that influence the spatiotemporal pattern and rate at which airbreathing aquatic foragers exploit their resources is important for understanding the dynamics of their communities. Diving decisions are particularly important because they influence both the amount of time spent underwater foraging and energetic costs, which may in turn affect habitat use decisions and thus the spatial pattern and magnitude of resource exploitation (see Boyd 1997, Heithaus \& Frid 2003).

*Address correspondence to this author at Florida International University, 3000 NE 151ST, North Miami, FL 33181, USA; Tel: 305-919-5234; Fax: 305-919-4030; E-mail: heithaus@fiu.edu

Special Issue Editor: John W. Laundre
In general, diving behavior has been assumed to be influenced almost exclusively by the trade-off between oxygen recovery at the surface and time spent at depth (e.g., Kramer 1988, Ydenberg \& Clark 1989, Houston \& Carbone 1992, Boyd et al. 1995, Thompson \& Fedak 2001). Indeed, most empirical research and models have focused on how divers should behave to maximize time at the bottom foraging or exploitation rates of prey. This trend has led to the development of several metrics of prey patch quality derived from diving behavior (e.g., Mori et al. 2005, 2007). Implicit in these metrics is the assumption that divers are only concerned with energy and oxygen stores and are immune to other effects, such as predation risk. While general predictions of models based on energetic currencies often are supported by empirical data (see Boyd 1997 for review), in many instances there are substantial deviations from predicted diving behavior. In some cases, these deviations might be explained by changes in diving behavior to reduce the risk of predation (e.g., Heithaus \& Frid 2003, Frid et al. 2007b, 2008). 
Despite the ubiquity of behavioral responses to predators (e.g., Lima 1998) and the likely importance of non-consumptive predator effects in marine communities (Heithaus et al. 2008), the possibility that divers modify their dive cycles in response to predation risk has historically been given little attention (but see Kramer \& Graham 1976, Le Boeuf \& Crocker 1996). Recent theoretical treatments, however, predict that optimal diving decisions under the risk of predation may differ substantially from those of a diver concerned only with energy intake (Heithaus \& Frid 2003, Frid et al. 2007a, 2007b, 2008).

For example, Frid et al. (2007a) used a combination of state-dependent modeling and empirical data to infer that harbor seal (Phoca vitulina richardsi) diving behavior might reflect an avoidance of deep but profitable foraging patches where predatory Pacific sleeper sharks (Somniosus pacificus) are abundant. However, direct comparisons of diving behavior across a gradient of predation risk are lacking. Such empirical studies are important for determining whether optimal diving models and an understanding of marine community dynamics require explicit accounting of predation risk (Frid et al. 2007b, Heithaus et al. 2008). For example, if dive cycles are modified in response to the risk of predation, then inferences about patch quality derived from diving metrics may not be appropriate if predators are present, which is usually the case (Heithaus \& Frid 2003, Frid et al. 2007b).

Here, we use spatial and temporal variation in the abundance of predatory tiger sharks (Galeocerdo cuvier) as a natural experiment (sensu Biro et al. 2005) to test whether pied cormorants (Phalacrocorax varius) modify their dive cycles in response to predation risk according to a priori theoretical predictions. We reasoned that, due to the inability of cormorants to be vigilant for tiger sharks while breathing and the propensity for tiger sharks to hunt prey at the surface (e.g., Simpfendorfer et al. 2001, Heithaus et al. 2002), cormorants should be at greatest risk from tiger sharks while at the surface in between dives (see Strong 1996, Heithaus \& Frid 2003). Under these conditions, the instantaneous risk of predation for a cormorant at the surface should remain constant, or even increase slightly due to the inability to be vigilant while breathing, with time spent at the surface during a single surface interval.

Accordingly, we tested the prediction, based on the model of Heithaus and Frid (2003), that cormorants should reduce dangerous surface intervals and, consequently, reduce dive durations, thereby increasing their diving rate (i.e., more frequent, shorter dives) when and where sharks are abundant. Shark Bay, Australia is well suited for testing this prediction because shark density, and therefore the probability that cormorants will encounter sharks, is characterized by marked spatial and temporal variability (Heithaus 2001, 2005, Heithaus et al. 2002, 2006, Wirsing et al. 2006).

\section{STUDY AREA}

The study was conducted in the relatively pristine seagrass ecosystem of the Eastern Gulf of Shark Bay, Australia (ca. $25^{\circ} 45^{\prime} \mathrm{S}, 113^{\circ} 44^{\prime} \mathrm{E}$, Fig. 1). The study area can be divided into two major habitat types: deep waters and shallow offshore banks. Deep waters range from $6-12 \mathrm{~m}$ in depth and have primarily sandy bottoms, while shallow habitats are typically less than $4.5 \mathrm{~m}$ in depth and are mostly covered by seagrass (Heithaus et al. 2006). Shark Bay supports large populations of tiger sharks and their prey, including pied cormorants. Tiger sharks often consume birds (Simpfendorfer 1992, Heithaus 2001, Simpfendorfer et al. 2001) and are the only known predator of cormorants at sea in the area (Heithaus 2005), but their abundance varies seasonally. Sharks are scarce or absent from June to August
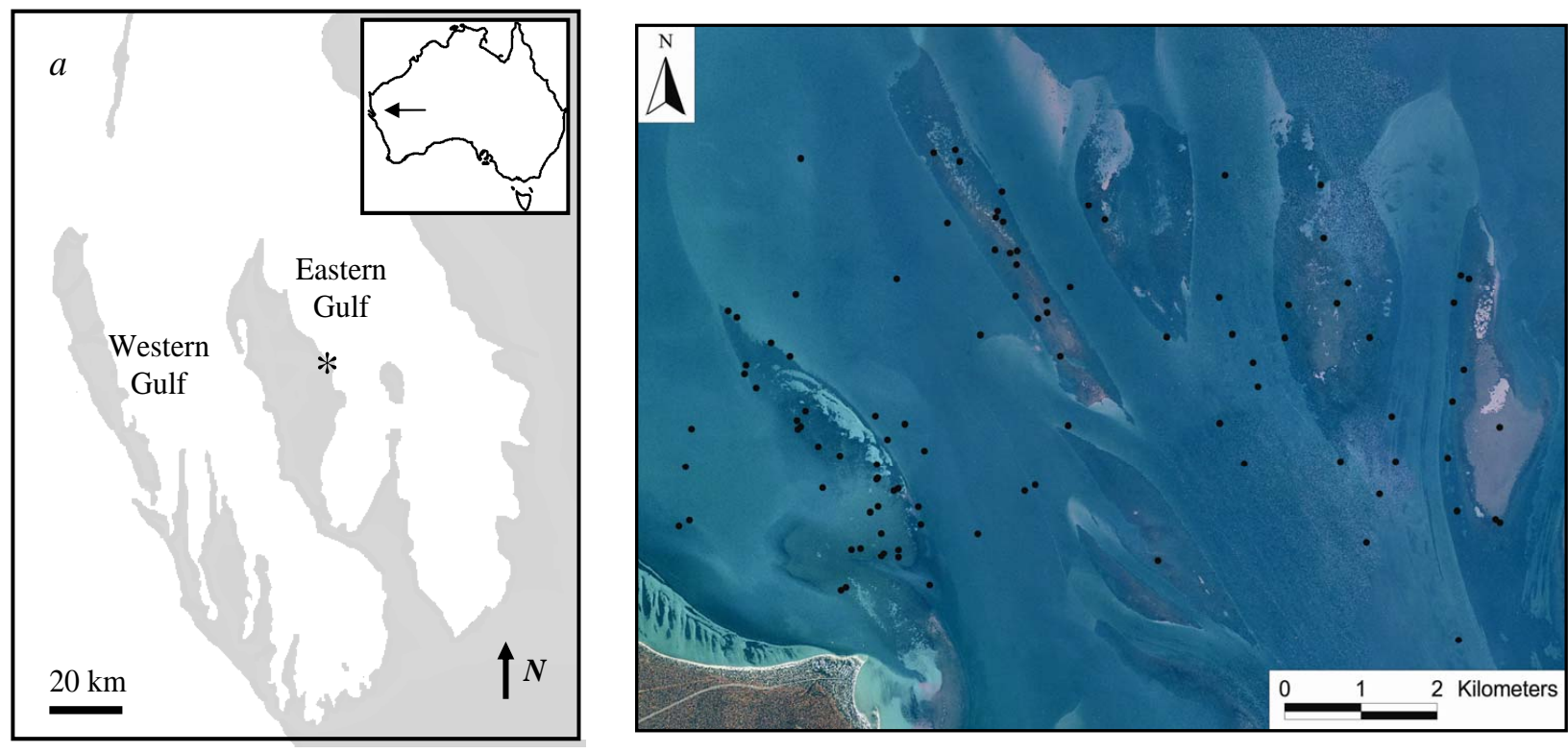

Fig. (1). (a) The study was conducted in the Eastern Gulf of Shark Bay, Western Australia, offshore of the Monkey Mia Dolphin Resort (*). Shark Bay is indicated by an arrow in the inset box. (b) The study area is made up of a mosaic of shallow banks and deeper waters. Shark fishing occurred in the channels between banks and the starting locations of cormorant follows are indicated with circles. 
and present in large numbers from September to May (Heithaus 2001, Wirsing et al. 2006). When present, tiger sharks are more abundant in shallow habitats than deep habitats (Heithaus et al. 2002).

Unlike tiger sharks, cormorant prey is abundant yearround. The distribution of prey across habitats is temporally stable with high abundance in shallow habitats and lower abundance in deep waters (Heithaus 2005). Importantly, the relative biomass available to cormorants in deep and shallow habitats does not change seasonally (i.e., does not vary with changes in shark abundance, Heithaus 2005). Therefore, it is possible to use both spatial and temporal variation in tiger shark abundance as a "natural experiment" to elucidate the effects of shark predation risk on the behavior of prey species (e.g., Heithaus 2005, Heithaus \& Dill 2006, Wirsing et al. 2007a, 2007b).

\section{METHODS}

From April 2006 to March 2007, we conducted 118 focal follows of cormorants during periods of lower shark abundance (June - August) and higher shark abundance (January - April). Follows were conducted in a $4.5 \mathrm{~m}$ research vessel with three observers. To ensure that all surfacing events could be recorded accurately, we only initiated follows when a lone foraging cormorant was located in relatively calm sea conditions. Additionally, the research vessel maintained a distance of $30 \mathrm{~m}$ from the bird to facilitate observations during the follow while minimizing potential disturbance. During each follow we recorded the bird's location, habitat type, and water depth every two minutes, as well as the exact time of each surfacing and submergence. A foraging dive was considered successful if the cormorant surfaced with a fish in its mouth. Follows were terminated when the focal cormorant flew away or showed obvious avoidance behaviors in response to our research vessel, another individual arrived, or we obtained 20 minutes of continuous observation. Only follows longer than 15 minutes and with at least 15 dives were included in analyses.

The abundance of tiger sharks was assessed using monthly catch rates on drumlines (see Heithaus 2001 for detailed methods). Briefly, sharks were caught on drumlines equipped with a single hook, baited primarily with Australian salmon (Arripis trutaceus), and deployed at dawn in six fishing zones throughout the study area. Lines were checked every two hours and all sharks caught throughout the day were measured, tagged, and released. This method is a reliable indicator of shark presence (Heithaus 2001). Catch rates on drumlines, however, cannot be used to assess shark habitat use due to differential rates of bait loss in deep and shallow habitats (Heithaus 2001, Heithaus et al. 2002). Therefore, the spatial pattern of risk to cormorants was determined using previously published data on habitat use of sharks that show temporally stable patterns of preference for shallow habitats over deep habitats (Heithaus et al. 2002, 2006).

\section{Statistical Analyses}

All focal follows $(n=118)$ were mapped into GIS (MapInfo, Professional version 4.5, MapInfo Corporation) to confirm habitat designations recorded in the field. Any follow that crossed into a second habitat was excluded from further analyses. Of the 105 focal follows that were used for analyses, 55 follows were completed during periods of lower shark abundance and 50 follows were carried out during periods of higher shark abundance. The distribution of dive durations from these follows was plotted (mean $=25.52$ seconds $\pm 0.18 \mathrm{SE}, \mathrm{n}=4175$ ) and outlying dives (above the $99.5 \%$ quantile and greater than 60.21 seconds, $n=23$ ) were excluded from analyses since these likely represented instances of missed surface intervals. We also excluded dives of less than 4 seconds (and below the $0.5 \%$ quantile, $n$ $=11$ ), because cormorants in this study never foraged successfully during such short dives. Finally, we excluded successful foraging dives $(\mathrm{n}=257)$ since fish handling time inflated the time spent at the surface following a successful dive. Thus, analyses were conducted on 3884 dives from 105 focal follows.

We used a general linear model (GLM) with mixed effects to determine the influence of habitat, shark catch rate, and their interaction on a variety of diving parameters that are predicted to change in response to variation in predation risk including post-dive surface interval (PDI), dive duration, and the ratio of dive duration to PDI. For these analyses, individual birds were treated as a random effect and habitat, shark catch rate, and their interaction were treated as fixed effects. Analyses were also carried out on data with each individual cormorant contributing a single mean value of diving parameters. Results were similar to those for the above model (that retained individual dives) and are therefore not presented. Finally, we tested the effect of habitat, shark catch rate, and their interaction on the diving rate of each focal individual. Values reported in the text are means \pm SE.

\section{RESULTS}

The time that cormorants spent at the surface (i.e., PDI) was influenced only by habitat (Table 1). Cormorants

Table 1. The Effect of Habitat, Shark Catch Rate (SCR), and their Interaction on Diving Metrics

\begin{tabular}{|c|c|c|c|c|}
\hline Metric & Effect & df & F & P \\
\hline \hline \multirow{3}{*}{$\begin{array}{c}\text { Post dive interval } \\
\text { (PDI) }\end{array}$} & Habitat & 1,104 & 48.23 & $<0.0001$ \\
\cline { 2 - 5 } & SCR & 1,104 & 1.32 & 0.25 \\
\cline { 2 - 5 } & Habitat $*$ SCR & 1,104 & 0.30 & 0.58 \\
\hline \multirow{4}{*}{\begin{tabular}{c} 
Dive duration \\
\cline { 2 - 5 }
\end{tabular}} & Habitat & 1,104 & 125.13 & $<0.0001$ \\
\cline { 2 - 5 } & SCR & 1,104 & 24.35 & $<0.0001$ \\
\hline \multirow{3}{*}{\begin{tabular}{c} 
Hive duration/PDI \\
\cline { 2 - 5 }
\end{tabular}} & Habitat & 1,104 & 0.84 & 0.36 \\
\cline { 2 - 5 } & SCR & 1,104 & 7.55 & 0.0072 \\
\cline { 2 - 5 } & Habitat* SCR & 1,104 & 5.19 & 0.025 \\
\hline \multirow{2}{*}{$\begin{array}{c}\text { Habitat } \\
\text { Diving rate }\end{array}$} & SCR & 1,104 & 84.42 & $<0.0001$ \\
\cline { 2 - 5 } & Habitat* SCR & 1,104 & 9.68 & 0.0024 \\
\hline
\end{tabular}


surfaced for an average of $16.9 \pm 1.1 \mathrm{sec}$ in deep habitats and $9.9 \pm 0.4 \mathrm{sec}$ in shallow habitats (Fig. 2). Post-dive surface intervals were not influenced by shark catch rate (Fig. 2). Dive duration, however, was influenced by an interaction of shark catch rate and habitat (Table 1). Dive duration was consistently higher in deep habitats $($ mean $=37.3 \pm 1.0 \mathrm{sec}$ ) than in shallow ones (mean $=24.0 \pm 0.8 \mathrm{sec})$. However, dive duration increased in shallow habitats as shark catch rates

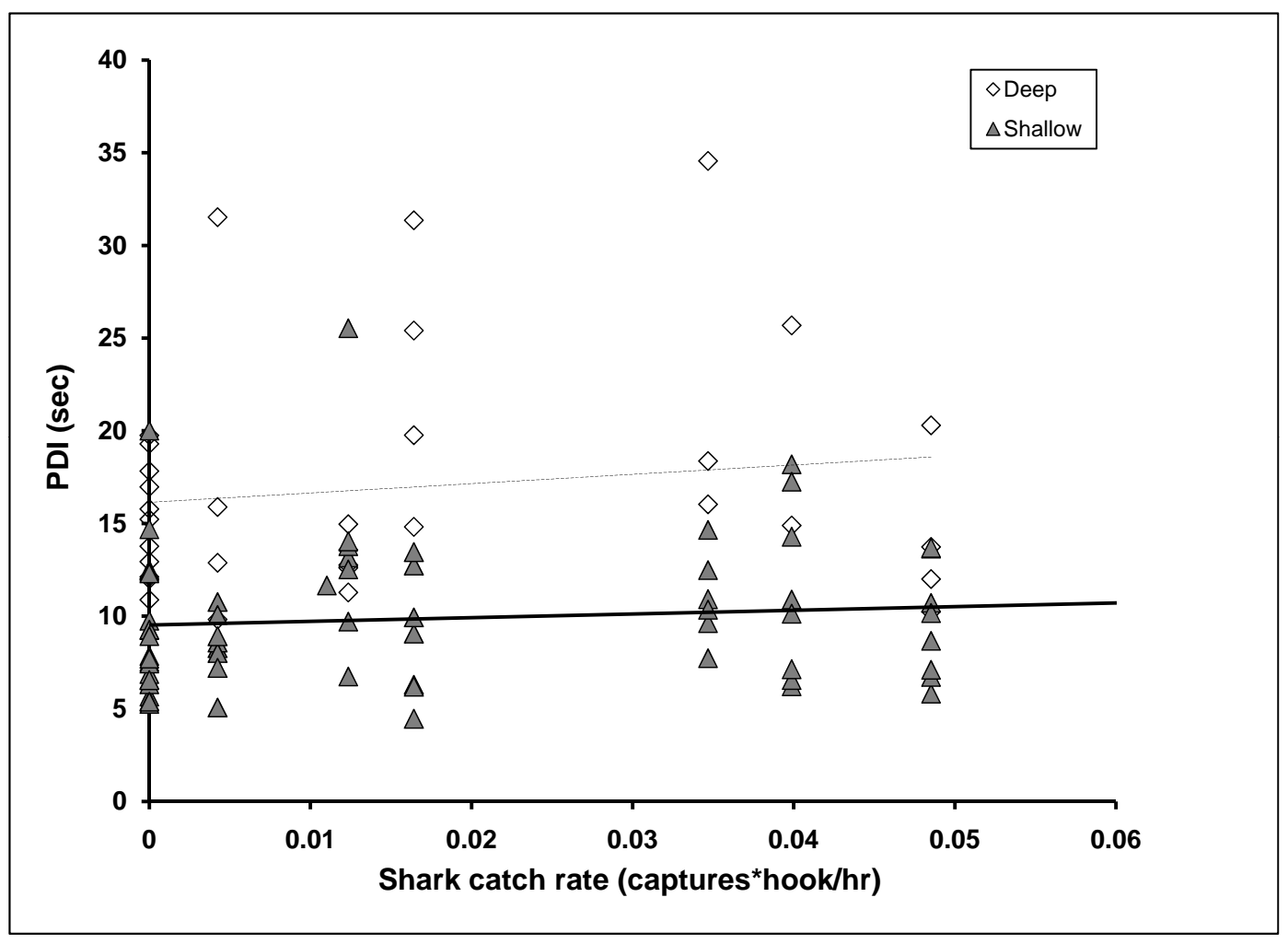

Fig. (2). The influence of habitat on average post-dive surface intervals (PDI) of pied cormorants ( $\mathrm{n}=3884$ dives from 105 individuals). Cormorants spent less time at the surface per dive in shallow habitats than deep habitats irrespective of variation in predation risk.

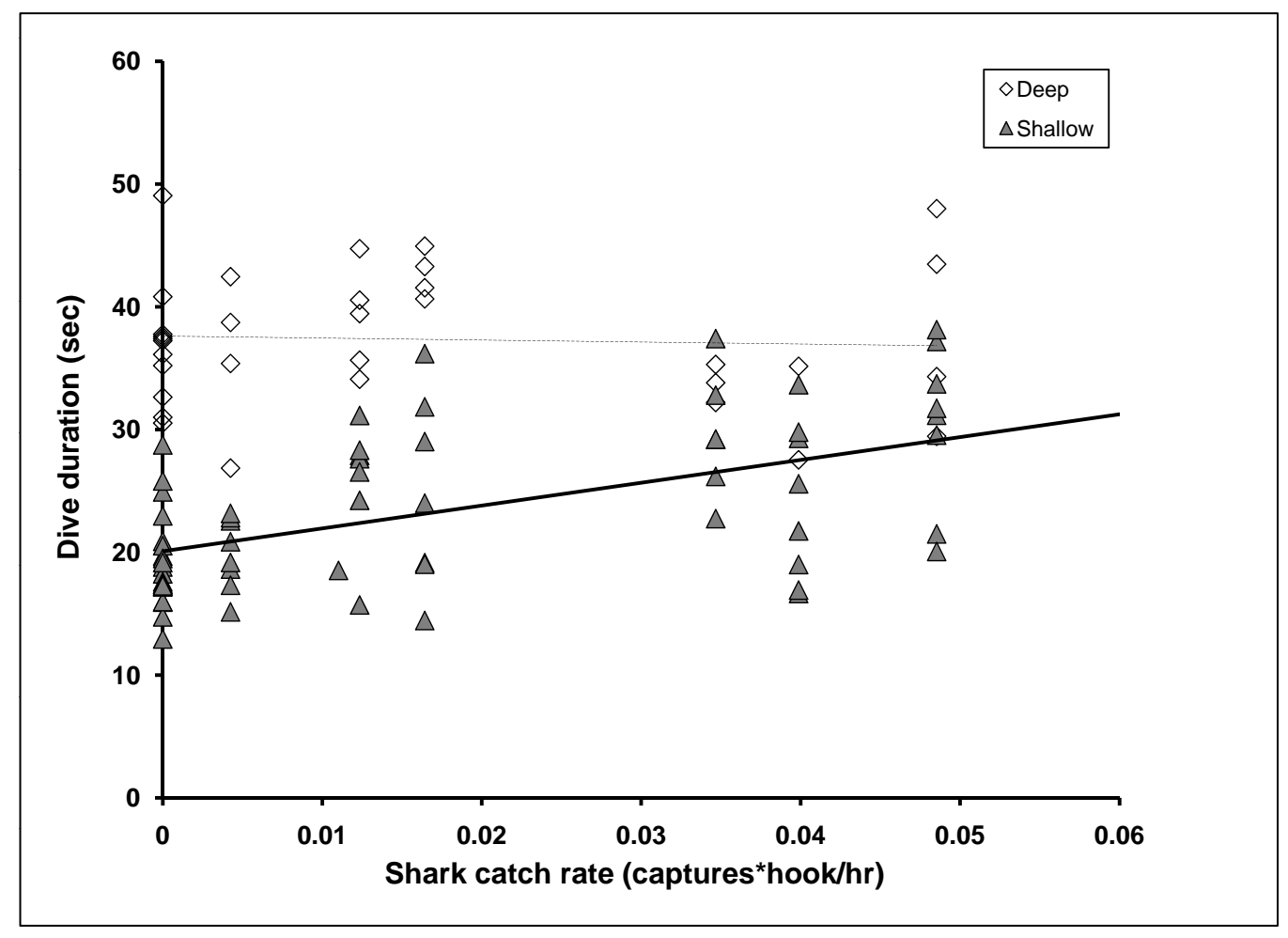

Fig. (3). The influence of habitat and shark catch rate on dive duration. Cormorants spent more time underwater in deep habitats, but those cormorants diving in shallow habitats had longer dive durations when sharks were present than when they were absent. 
rose but remained consistent in deep habitats regardless of shark catch rates (Fig. 3). The ratio of dive duration to PDI also was influenced by the interaction of habitat and shark catch rate (Table 1). Cormorants diving in shallow habitats increased the dive duration/PDI ratio as shark catch rate increased, while those in deep habitats did not (Fig. 4). Lastly, diving rate was also influenced by the interaction of habitat and shark catch rate (Table 1), with cormorants in shallow habitats making fewer dives as shark catch rate increased (Fig. 5).

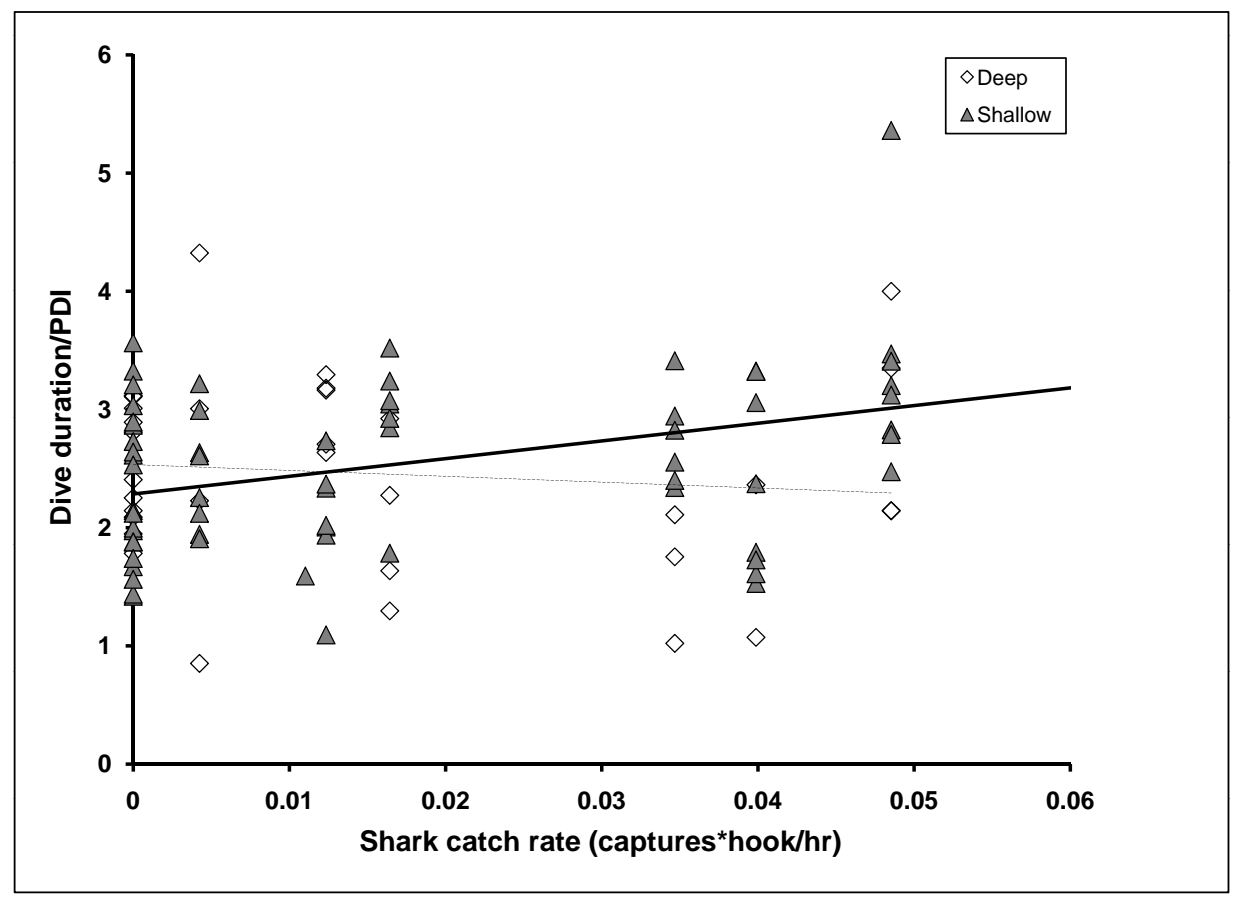

Fig. (4). The influence of habitat and shark catch rate on the ratio of dive duration/PDI. Cormorants in shallow habitats decreased the proportion of time they spent at the surface per dive as shark abundance increased.

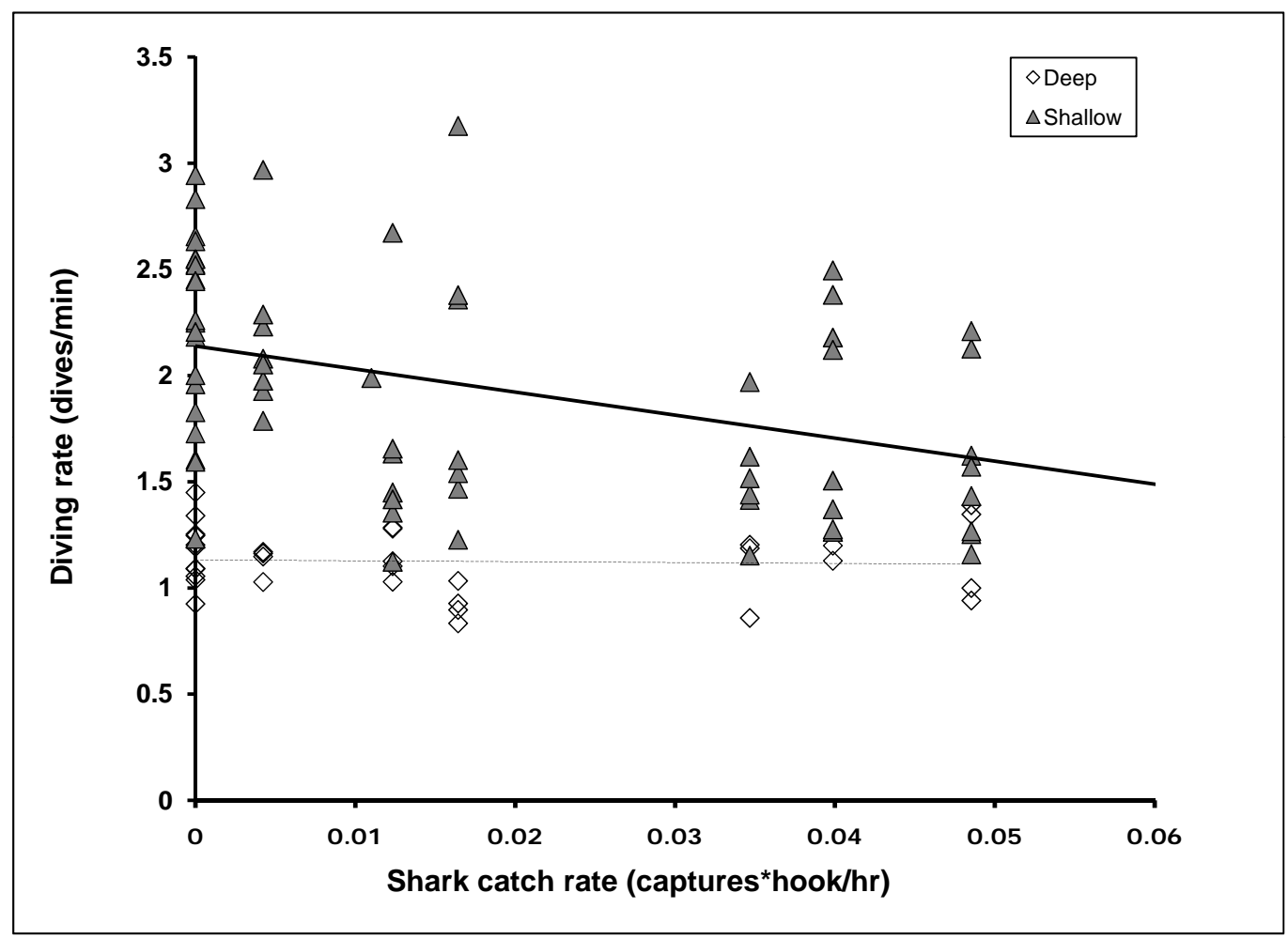

Fig. (5). The influence of habitat and shark catch rate on the rate of diving (dives per minute). Diving rates remained consistent in deep habitats but decreased as shark catch rate increased in shallow habitats. 


\section{DISCUSSION}

For several decades, there has been considerable interest in the factors influencing diving decisions (e.g., physiology, Kooyman et al. 1981, Kramer 1988, prey distribution, Mori 1998), leading to intensive empirical work both in the laboratory and the field. Despite pioneering work by Kramer and colleagues (Kramer and Graham 1976, Kramer et al. 1983) that demonstrated that bimodally-breathing species (i.e., those that can extract oxygen from water and breathe air) reduce their rate of surface breathing when threatened by both aerial and subsurface predators, the possibility that the diving behavior of species that rely solely on atmospheric oxygen might be influenced by predation risk has only recently been considered. Yet, with rare exceptions, aquatic foragers that breathe air are mesopredators and must manage the risk of predation along with energetic concerns (see Heithaus \& Frid 2003, Frid et al. 2007b).

We used temporal and spatial variation in predator (tiger shark) abundance to field-test a priori predictions of how cormorants should modify diving behavior in response to varying predation risk. When tiger sharks were absent, cormorants conformed to basic predictions of optimal diving theory, making longer dives with longer surface intervals (PDIs) in deeper waters where travel times to prey would be greater. We predicted, based on the models of Heithaus and Frid (2003), that in order to reduce their exposure to predators during dangerous surfacing events, cormorants would decrease their PDI when and where sharks were abundant relative to times and places where sharks were scarce. Specifically, model predictions suggested that birds would reduce surface intervals (and dive durations), resulting in more, shorter dives during periods of high predation risk in order to take advantage of the brief window upon first surfacing during which the bird could be relatively certain that risk was low (i.e., through vigilance while surfacing). Instead, we found that birds maintained consistent PDIs but increased dive duration as shark risk increased, resulting in fewer, longer dives when sharks were present.

Why would birds not adjust time at the surface when spending more time underwater? In general, in order to increase dive duration (to gain foraging time within a patch or obtain access to deeper prey), surface time is increased to allow for more oxygen loading (e.g., Wilson \& Wilson 1988, Croll et al. 1992, Chappell et al. 1993, Boyd et al. 1995, Boyd 1997). The most likely explanation for the mismatch between theoretical predictions and empirical data is the structure of the Heithaus and Frid (2003) model. First, the model asks how individuals should modify their time spent at the surface in response to predators for a given travel time and assumes that the diver will adjust its bottom time based on oxygen replenishment rates to maximize dive time. Therefore, the model assumes that 1) when divers are not threatened with the risk of predation they will dive at (and not below) their aerobic dive limit (ADL) and 2) divers do not use anaerobic respiration. Thus, the structure of the model does not allow for the type of adjustment to dive cycles observed in our study (i.e., longer dives for a given surface interval).

Anaerobic metabolism can be used adaptively by divers to maximize energy intake rates (e.g., Western grebes, Aechmophorus occidentalis, Ydenberg \& Clark 1989, hooded seals Cystophora cristala, Thompson \& Fedak 2001) and likely is important for divers optimizing energy and safety. For example, the marginal value of continuing to search for prey (or continuing a chase) while submerged should be higher, even if the bird must use anaerobic respiration, when surfacing carries not only the cost of lost foraging time but also the risk of predation. For diving species that cannot easily leave the water for refuge from predation (e.g., marine mammals, sea turtles), anaerobic dives may not be beneficial because doing so would result in a prolonged recovery period at the surface (Boyd 1997). However, seabirds that accumulate lactic acid after completing a series of anaerobic foraging dives have the option to fly to safety and recover on land after foraging. For birds choosing this option, recovery costs are likely outweighed by the reduction in total time exposed to predators. Based on our data, it is not possible to determine whether birds in shallow habitats were diving well below their ADL during times when sharks were scarce and then increased their effort towards their ADL as sharks became more abundant or if they began using anaerobic dives when sharks were present. Studies of pied cormorant congeners (e.g., Kerguelen shags, Phalacrocorax verrucosus, Crozet shags, $P$. melanogenis) suggest that, although dive times can vary considerably for a particular surface time, cormorant species tend to dive in a manner close to that which maximizes time at the bottom within aerobic thresholds (Cook et al. 2008). Thus, cormorants in our study area may be relying more heavily on anaerobic respiration as shark abundance increases. Further studies of the diving physiology of cormorants in Shark Bay are needed, however, to more fully explore this possibility. For example, dive durations were relatively short across the range of shark abundances. Thus, increases in dive duration may have been accomplished through increased rates of oxygen uptake after longer dives (Parkes et al. 2002) when sharks were present or by cormorants diving below their ADL in periods when sharks were largely absent.

Spatio-temporal variation in the diving behavior of cormorants cannot be attributed to variation in water temperature or cormorant prey. Although water temperature in Shark Bay increases as shark abundance increases, the changes in cormorant diving behavior that we observed are not consistent with the expected responses to variation in water temperature. If water temperature was driving cormorant diving patterns, we would have expected 1) longer surface times in both habitats during periods of low shark abundance (cooler waters) for thermoregulation and 2) identical changes in diving behavior across habitats (i.e., no significant interaction of shark catch rate and habitat) because temperatures are similar in the two habitats. Neither of these predictions is supported by our data.

Similarly, changes in prey abundance cannot explain variation in cormorant diving. Despite differences in the overall abundance of cormorant prey between shallow and deep habitats, the distribution of prey between habitats does not vary with changes in tiger shark abundance (Heithaus 2005). Thus, a significant influence of the interaction of shark catch rate and habitat would not be expected based on changes in prey abundance. In fact, because cormorant abundance increases relative to their food in deep habitats when sharks are more abundant (Heithaus 2005), we might 
expect changes in diving behavior that would be quite different than those we observed. Specifically, we would expect that cormorants in deep habitats would have to work harder to find prey (i.e., longer dive times), because prey is relatively scarce and the number of competitors is higher when sharks are present.

Our study adds to a growing understanding of the important role of predation risk in influencing diving patterns of obligate air-breathing aquatic foragers. For example, Frid and colleagues have used empirically parameterized optimality models to show that foraging behavior and diving behavior of two north Pacific pinnipeds - harbor seals and Steller sea lions (Eumetopias jubatus) are influenced by the presence of deepwater sleeper sharks (Frid et al. 2007a, 2009). Also, a simple model suggested that mismatches between theoretical predictions based on energetic currencies and observed diving behavior of other pinnipeds might be explained by responses to predators (Frid et al. 2007b). Furthermore, studies of marine mammal responses to human disturbance (e.g., motorboats), which often are analogous to those made in response to natural predators (Frid and Dill 2002), suggest that divers modify their dive cycles in response to perceived threats. For example, bottlenose dolphins (Tursiops spp.) in New Zealand increase dive duration when disturbed by motorboats (Lusseau 2003) - a response similar to that of cormorants at risk from sharks.

The evidence that predation risk is important in shaping the diving behavior of species that are often considered "top predators" has two important implications. First, although there undoubtedly is considerable interspecific variation in the magnitude of predation risk to diving species, the potential influence of predation risk on divers must be explicitly considered (Frid et al. 2007b). Second, diving behavior cannot be used as a reliable indicator of prey patch quality in locations where predators might be important. Metrics of prey patch quality based on the idea that, all else being equal, animals will spend more time foraging (e.g., underwater) in high quality patches of prey than in patches of average quality have been empirically validated (Mori et al. 2005, 2007), but some of these tests were in situations where divers faced little or no predation risk (e.g., Weddell seals, Leptonychotes weddelli, diving from remote breathing holes, Mori et al. 2005, 2007). Our results suggest that these indices may be misleading when applied to cases in which aquatic foragers must optimize energy gain and predator avoidance, which is arguably much more common. For example, had we applied these indices to cormorants in our study, we would have erroneously concluded that shallow patches were of higher quality during periods when sharks were abundant than when sharks were scarce because dive durations were relatively longer. Data on prey availability and our understanding of shark predation risk to cormorants allowed us to reject this explanation. Modified metrics that incorporate how predation risk may influence dive behavior and foraging time may be more realistic in predicting patch quality.

In conclusion, it is becoming increasingly apparent that large marine diving species are not immune to the effects of predation risk, even if their populations experience low predation rates (Frid et al. 2007b, Heithaus et al. 2008).
Since these species often are upper trophic level consumers or large herbivores, modifications to their diving behavior in response to predation risk are likely to cascade through communities and therefore may influence both population and ecosystem dynamics (e.g., Bowen 1997, Moran \& Bjorndal 2007, Heithaus et al. 2008). By implication, ignoring the effects of predation risk on diving behavior may inhibit the prediction of diver responses and ecosystem dynamics following changes to predator populations. For example, the removal of top predators may create "riskreleased systems" in which the behavior of some diving species is no longer regulated by risk, leading to changes in resource exploitation by divers and ultimately changes in community structure (Frid et al. 2008). Therefore, our understanding of diving behavior and the roles that divers play in communities will be greatly enhanced by the recognition that divers may often be preyed upon and by the appreciation of the influence of predation risk on their behavior, including diving decisions.

\section{ACKNOWLEDGEMENTS}

This research was funded by the National Science Foundation (OCE0526065, 2005022771, OCE0745606) and Florida International University. We thank the Monkey Mia Dolphin Resort for logistical support. We also thank our many field assistants. This research was carried out under Western Australia Department of Environment and Conservation permits and FIU IACUC permission. This paper is contribution 40 of the Shark Bay Ecosystem Research Project.

\section{REFERENCES}

Aragones, LV \& Marsh, H (2000) Impact of dugong grazing and turtle cropping on tropical seagrass communities. Pacific Conservation Biology, 5, 277-288.

Biro, PA, Post, JR \& Abrahams, MV (2005) Ontogeny of energy allocation reveals selective pressure promoting risk-taking behaviour in young fish cohorts. Proceedings of the Royal Society B: Biological Sciences, 272, 1443-1448.

Bowen, WD (1997) Role of marine mammals in aquatic ecosystems. Marine Ecology Progress Series, 158, 267-274.

Boyd, IL (1997) The behavioural and physiological ecology of diving. Trends in Ecology and Evolution, 12, 213-217.

Boyd, IL, Reid, K \& Bevan, RM (1995) Swimming speed and allocation of time during the dive cycle in Antarctic fur seals. Animal Behaviour, 50, 769-784.

Chappell, MA, Shoemaker, VH, Janes, NN, Bucher, TL \& Maloney, SK (1993) Diving behavior during foraging in breeding adelie penguins. Ecology, 74, 1204-1215.

Cook, TR, Lescroël, A, Tremblay, Y \& Bost, C (2008) To breathe or not to breathe? Optimal breathing, aerobic dive limit and oxygen stores in deep-diving blue-eyed shags. Animal Behaviour, 76, 565-576.

Croll, DA, Gaston, AJ, Burger, AE \& Konnoff, D (1992) Foraging behavior and physiological adaptation for diving in thick-billed murres. Ecology, 73, 344-356.

Frid, A \& Dill, LM (2002) Human-caused disturbance stimuli as a form of predation risk. Conservation Ecology, 6, http://www.consecol.org/ Journal/vol6/iss1/art11/print.pdf.

Frid, A, Dill, LM, Thorne, RE \& Blundell, GM (2007a) Inferring prey perception of relative danger in large-scale marine systems. Evolutionary Ecology Research, 9, 635-649.

Frid, A, Heithaus, MR \& Dill, LM (2007b) Dangerous dive cycles and the proverbial ostrich. Oikos, 116, 893-902.

Frid, A, Baker, GG \& Dill, LM (2008) Do shark declines create fearreleased systems? Oikos, 117, 191-201. 
Frid, A., Burns, J, Baker, GG \& Thorne, RE (2009) Predicting synergistic effects of resources and predators on foraging decisions by juvenile Steller sea lions. Oecologia, 158, 775-786.

Heithaus, MR (2001) The biology of tiger sharks, Galeocerdo cuvier, in Shark Bay, Western Australia: sex ratio, size distribution, diet and seasonal changes in catch rates. Environmental Biology of Fishes, $61,25-36$

Heithaus, MR (2005) Habitat use and group size of pied cormorants (Phalacrocorax varius) in a seagrass ecosystem: possible effects of food abundance and predation risk. Marine Biology, 147, 27-35.

Heithaus, MR \& Dill, LM (2006) Does tiger shark predation risk influence dolphin habitat use at multiple spatial scales? Oikos, 114, 257-264.

Heithaus, MR \& Frid, A (2003) Optimal diving under the risk of predation. Journal of Theoretical Biology, 223, 79-93.

Heithaus, MR, Dill, LM, Marshall, GJ \& Buhleier, BM (2002) Habitat use and foraging behavior of tiger sharks (Galeocerdo cuvier) in a subtropical seagrass ecosystem. Marine Biology, 140, 229-236.

Heithaus, MR, Hamilton, IM, Wirsing, AJ \& Dill, LM (2006) Validation of a randomization procedure to assess animal habitat preferences: microhabitat use of tiger sharks in a seagrass ecosystem. Journal of Animal Ecology, 75, 666-676.

Heithaus, MR, Frid, A, Wirsing, AJ \& Worm, B (2008) Predicting ecological consequences of marine top predator declines. Trends in Ecology and Evolution, 4, 202-210.

Houston, AI \& Carbone, C (1992) The optimal allocation of time during the diving cycle. Behavioral Ecology, 3, 255-265.

Kooyman, GL, Castellini, MA \& Davis, RW (1981) Physiology of diving in marine mammals. Annual Review of Physiology, 43, 343-356.

Kramer, DL (1988) The behavioral ecology of air breathing by aquatic animals. Canadian Journal of Zoology, 66, 89-94.

Kramer, DL \& Graham, JB (1976) Synchronous air breathing, a social component of respiration in fishes. Copeia, 1976, 689-697.

Kramer, DL, Manley, D \& Bourgeois, R (1983) The effect of respiratory mode and oxygen concentration on the risk of aerial predation in fishes. Canadian Journal of Zoology, 61, 653-665.

Le Boeuf, BJ \& Crocker, DE (1996) Diving behavior of elephant seals: implications for predator avoidance. In: Klimley, AP \& Ainley, AD (Eds) Great White Sharks: The Biology of Carcharodon carcharias, Academic Press: New York, 193-205.

Lima, SL (1998) Nonlethal effects in the ecology of predator-prey interactions. Bioscience, 48, 25-34.

Lusseau, D (2003) Male and female bottlenose dolphins Tursiops spp. have different strategies to avoid interactions with tour boats in Doubtful Sound, New Zealand. Marine Ecology Progress Series, 257, 267274.

Moran, KL \& Bjorndal, KA (2007) Simulated green turtle grazing affects nutrient composition of the seagrass Thalassia testudinum. Marine Biology, 150, 1083-1092.

Mori, Y (1998) Optimal choice of foraging depth in divers. Journal of Zoology, 245, 279-283.
Mori, Y, Wantanabe, Y, Mitani, Y, Sato, K, Cameron, MF \& Naito, Y (2005) A comparison of prey richness estimates for Weddell seals using diving profiles and image data. Marine Ecology Progress Series, 295, 257-263.

Mori, Y, Mitani, Y, Watanabe, Y \& Sato, K (2007) A behavioral indicator of prey patch richness derived from diving behavior: the proportion of residence time to the standard time. Israel Journal of Ecology and Evolution, 53, 347-354.

Parkes, R, Halsey, LG, Woakes, AJ, Holder, RL \& Butler, PJ (2002) Oxygen uptake during post dive recovery in a diving bird Aythya fuligula: implications for optimal foraging models. Journal of Experimental Biology, 205, 3945-3954.

Preen, A (1995) Impacts of dugong foraging on seagrass habitats: observational and experimental evidence for cultivation grazing. Marine Ecology Progress Series, 124, 201-213.

Simpfendorfer, CA (1992) Biology of tiger sharks (Galeocerdo cuvier) caught by the Queensland shark meshing program off Townsville, Australia. Australian Journal of Marine and Freshwater Research, 43, 33-43.

Simpfendorfer, CA, Goodreid, AB \& McAuley, RB (2001) Size, sex, and geographic variation in the diet of the tiger shark (Galeocerdo cuvier) in Western Australian waters. Environmental Biology of Fishes, 61, 37-46.

Strong, WR (1996) Shape discrimination and visual predatory tactics in white sharks. In: Klimley, AP \& Ainley, AD (Eds) Great White Sharks: The Biology of Carcharodon carcharias, Academic Press: New York, 229-240.

Thayer, GW, Bjorndal, KA, Ogden, JD, Williams, SL \& Zieman, JC (1984) Role of larger herbivores in seagrass communities. Estuaries, 7, 351-376.

Thompson, D \& Fedak, MA (2001) How long should a dive last? A simple model of foraging decisions by breath-hold divers in a patchy environment. Animal Behaviour, 61, 287-296.

Wilson, RP, \& Wilson, MPT (1988) Foraging behaviour in four sympatric cormorants. Journal of Animal Ecology, 57, 943-955.

Wirsing, AJ, Heithaus, MR \& Dill, LM (2006) Tiger shark (Galeocerdo cuvier) abundance and growth in a subtropical embayment: evidence from 7 years of standardized fishing effort. Marine Biology, 149, 961-968.

Wirsing, AJ, Heithaus, MR \& Dill, LM (2007a) Fear factor: do dugongs (Dugong dugon) trade food for safety from tiger sharks (Galeocerdo cuvier)? Oecologia, 153, 1031-1040.

Wirsing, AJ, Heithaus, MR \& Dill, LM (2007b) Living on the edge: dugongs prefer to forage in microhabitats that allow escape from rather than avoidance of predators. Animal Behavior, 74, 93-101.

Ydenberg, RC \& Clark, CW (1989) Aerobiosis and anaerobiosis during diving by western grebes: an optimal foraging approach. Journal of Theoretical Biology, 139, 437-449.

Received: August 31, 2009

Revised: December 16, 2009

Accepted: January 25, 2010

(C) Dunphy-Daly et al.; Licensee Bentham Open.

This is an open access article licensed under the terms of the Creative Commons Attribution Non-Commercial License (http://creativecommons.org/licenses/by$\mathrm{nc} / 3.0 /$ ), which permits unrestricted, non-commercial use, distribution \& reproduction in any medium, provided the work is properly cited. 